\title{
Meeting the needs of the Millennials and Generation Z: gamification in tourism through geocaching
}

Heather Skinner, David Sarpong and Gareth R.T. White

\begin{abstract}
Purpose - The purpose of this paper is to present a conceptual framework based on an understanding of the principles of popular mobile-enabled games, indicating how organisations in the tourism sector could meet the needs of Millennials and Generation $Z$ through engaging with the existing gamified location-based practice of geocaching as an information and communication technology enabled gamified enhancement to the destination experience.

Design/methodology/approach - As a primarily conceptual paper, the authors take an inductive qualitative approach to theory building based on the understanding of an existing practice (geocaching) that is undertaken among a community of practitioners (geocachers), which results in the presentation of a conceptual framework, which is the theory itself that the authors have constructed from the understanding of what is going on and which principles can then be applied across other tourism practices.

Findings - Findings indicate that through engaging with geocaching, smaller entrepreneurial businesses even in non-urban destinations that fall outside of the remit of smart city developments, and in tourism destinations on the less technologically enabled or resource-rich side of the digital divide, can reap the benefits associated with employing the principles and practices associated with smart tourism to meet the needs of this new generation of tourism consumers who seek richer digital and often gamified tourism experiences.
\end{abstract}

Originality/value - This paper fills a gap in the literature regarding the way many different types of tourism destinations could meet the needs of Millennials and Generation $Z$ tourists.

Keywords Gamification, Millennials, Rural tourism, Generation Z, Geocaching, Smart tourism

Paper type Research paper

\section{Introduction}

Across Europe the majority of what has been termed "smart tourism" developments have focussed on the urban, and the creation of smart cities (Gretzel et al., 2015), at the expense of a focus on how other types of destination may engage with these consumers through the use of mobile and web-based technologies. Moreover, it is also in Europe where geocaching, a location-based leisure sport enabled by mobile global positioning system (GPS) based technology, is already a well-established practice, where much of the participant data on the subject originates (Cord et al. , 2015), and where this practice can open up the extra-urban space to business development opportunities. Furthermore, with Millennials and Generation Z also being those that seek adventure, and gamified experiences involving riddle solving and overcoming physical challenges, we propose that geocaching as a pastime which appeals to many different generations, could help provide a whole-family destination experience, as well as an experiential destination enhancement specifically to these younger tourists. The aim of this paper is, therefore, through an analysis of the practice of geocaching drawn from a range of global examples but contextualised to European destinations, to present a conceptual framework that can help a wide range of organisations, including smaller entrepreneurial businesses in non-urban destinations that fall outside of the remit of smart city developments,
Heather Skinner is the Chair: Visiting Places SIG at the Institute of Place Management, Manchester Metropolitan University Business School, Manchester, UK.

David Sarpong is a Reader in Strategic Management at the Brunel Business School, Brunel University,

Uxbridge, UK.

Gareth R.T. White is a Reader in Operations and Information Management at the Faculty of Business and Society, University of South Wales, Pontypridd, UK.
Received 10 December 2017 Accepted 13 December 2017

(C) Heather Skinner, David Sarpong and Gareth R.T. White. Published by Emerald Publishing Limited.

This article is published under the Creative Commons Attribution (CC BY 4.0) licence. Anyone may reproduce, distribute, translate and create derivative works of this article (for both commercial and non-commercial purposes), subject to full attribution to the original publication and authors.

The full terms of this licence may be seen at http://

creativecommons.org/licences/by/ 4.0/legalcode 
and in tourism destinations on the less technologically enabled or resource-rich side of the digital divide, to reap the benefits associated with employing the principles and practices associated with smart tourism to meet the needs of this new generation of tourism consumers who seek richer digital and often gamified tourism experiences.

The following sections of this paper address some of the theoretical underpinnings that we have drawn from in the literature on smart tourism, the gamification and of experiences, the characteristics and needs of Millennials and Generation Z, and their engagement with gamified augmented reality (AR) applications.

Because this is primarily a conceptual paper, we have based our understanding of the practice of geocaching from a range of global examples where we believe this could be applied in a European tourism context. Thus we have built a theory, presented as a conceptual framework, that explains geocaching as a community of practice, in order to explain the activities associated with the practice. Despite wide engagement with geocaching as a practice, this fills a gap in the literature conceptualising geocaching in theory. Based on this understanding, this paper also fills a gap in knowledge regarding the way many different types of tourism destinations could meet the needs of Millennials and Generation Z tourists through adopting more gamified tourism experiences.

\section{Smart tourism}

In future, tourism products will be required to proactively take into consideration mobile developments in order to ensure that they to respond to the demands of travellers during each phase of their holidays (Egger and Buhalis, 2008, p. 417).

Much of the extant literature concerned with the use of information and communication technology (ICT) in tourism is focussed on the development of what has been termed "smart tourism destinations" (Buhalis and Amaranggana, 2014). Although this body of literature is still relatively new it is growing, and various different research topics are emerging. For example, there is an emerging strand within this body of literature that considers the use of augmented and virtual reality (VR) in the gamification of ICT-enabled tourism. However, overall, the focus across all of this literature tends to be on the urban, focussing on the smart city rather than on the wider deployment of ICT towards facilitating smart tourism initiatives in more regional or rural destinations. Yet not all tourism destinations are at the same advanced stage of technological development, and many non-urban and less developed destinations do not have the technological infrastructure or other resources to afford them the ability to reap the same benefits allowed to smart cities. This is particularly the case in Europe, where the majority of smart tourism developments focus on the urban, and the creation of smart cities (Gretzel et al., 2015), at the expense of a focus on how other types of destination may engage with these consumers through the use of mobile and web-based technologies. Moreover, it is also in Europe where geocaching, a location-based leisure sport enabled by mobile GPS-based technology, is already a well-established practice, where much of the participant data on the subject originates (Cord et al., 2015), and where this practice can open up the extra-urban space to business development opportunities.

Due to its basis in geo-location technology, geocaching also develops such physical spaces as places where virtual groups may meet and interact through engagement with this practice. There also appears to be a gap in the literature regarding the way many different types of tourism destinations are now able to meet the needs of Millennials and Generation Z, digital natives who are immersed in the use of Web 2.0 technologies.

Globalisation, communication, mobility and virtuality have been identified as the four dominant trends in our contemporary society and economy, and thus our world is being transformed and indeed revolutionised by developments in information and communication technologies (ICT) (Egger and Buhalis, 2008). In tourism, these developments have been applied mostly with regard to advancements in mobile technology. However, not all tourism destinations are at the same level of technological advancement. The smart tourism literature tends to stem from the literature on smart cities, and thus is heavily focussed on urban destinations (Buhalis and Amaranggana, 2014). While urban tourism remains an important area of research focus, rural tourism destinations continue to receive far less attention in the literature (Greaves and Skinner, 2010; Quadri-Felitti and Fiore, 2016). 
Buhalis (2000) has identified the need for integration of effort amongst a range of service providers in order to create a successful tourist product. In rural areas, delivering successful tourist experiences tends to rest more in the hands of individual business, typically small-business entrepreneurs, but whose individual efforts also need to complement the efforts of the area's other individual small businesses. There remains however a gap in the literature regarding the way multi-stakeholder supplier groups successfully deliver consistency in the tourism experience (Quadri-Felitti and Fiore, 2016). One of the key findings from Quadri-Felitti and Fiore's research undertaken into this issue with rural wine tourism suppliers was that individual business offerings were deemed not to be as strong as that offered by the destination in its entirety, thus not only in the perception of tourism business suppliers, but also in the perception of tourists themselves, the whole becomes greater than the sum of its parts:

Smart Tourism Destinations take advantage of: (1) Technology embedded environments; (2) Responsive processes at micro and macro levels (3) End-user devices in multiple touch-points; and (4) Engaged stakeholders that use the platform dynamically as a neural system (Buhalis and Amaranggana, 2014, p. 557).

To be successful, smart tourism destinations rely upon effective leadership that fosters entrepreneurship and innovation, and which leverages the destination's social and human capital (Boes et al., 2015). For example, a smart tourism destination could offer a highly sophisticated electronically enabled tour guide system that could be accessed from the cloud (Buhalis and Amaranggana, 2014). However, such an innovative introduction would require the development of a technological infrastructure that may be beyond the immediate reach of destinations on the less technologically enabled or resource-rich side of the digital divide. How these poorer, rural, less-developed, or less technologically enabled destinations may reap benefits from smaller scale developments towards smart tourism, along with ways in which such developments could be introduced in a way that democratises economic and social benefits for smaller enterprises and societies in a sustainable way, is most definitely under-researched and under-theorised in the current extant literature (Gretzel et al., 2015).

\section{Gamification}

Another development linked to advances in ICT is the notion of "gamification" in tourism. Most of the more recent literature on this topic considers the issue of gamification specifically alongside developments in AR and VR. Incorporating VR will often involve the use of headsets to immerse the player (virtual tourist) in an experience. AR in tourism often involves the use of quick response (QR) codes to guide tourists to various points of interest in a destination (Linaza et al., 2014), although AR "technology is just on the verge of being implemented in a meaningful way in the tourism industry" (Han et al., 2014, p. 511), and gamification in general in tourism remains in its infancy (Xu et al., 2014). Thus, for many rural destinations, less-developed destinations, and also for tourism destinations on the less technologically enabled or resource-rich side of the digital divide, it is much more difficult to reap the benefits associated with smart tourism, or to wholly embrace VR or AR in efforts towards gamification of the tourist experience in any meaningful way, particularly when attempting to target Millennials and Generation Z.

\section{Millennials and Generation Z}

Millennials, also referred to as Generation $\mathrm{Y}$, have been variously defined as: "People born between 1980-1990 [...] the first generation of so called 'digital natives' " (Cord et al., 2015, pp. 158-9); those born between 1977 and 1996 (Valentine and Powers, 2013); born between 1981 and 1995 (Solka et al., 2011); or between 1977 and 1994 (Neuborne 1999; Williams and Page, 2011). Thus a broad understanding of Millennials is that they would range from no younger than 21 and no older than 40 years of age today in 2017. The post-millennial Generation Z (Tapscott, 2009) are variously defined as those people born between the mid-1990s to the early 2010s and therefore can be aged ranging from 7 to 22 years old today in 2017. Thus, depending on what definitions are used for start and end birth years of each different generational category, there could be some cross-over between younger Millennials and older Generation Z, and at the older age range Millennials could be parents of Generation Z children. However, whatever the definitional categories of precise age ranges, Millennials and Generation Z are both familiar with 
internet-based technologies, and while new technologies are not replacing older ones, Millennials tend to prefer communication via text or voice, whereas Generation Z are happier using video communication, and spend a great deal of time on smart phones and accessing social media (Thomas, 2011). Generation Z in particular, along with younger Millennials, also participate in different leisure activities than older generations, for example, in the UK young people aged 16-24 tend to rank cultural activities such as visiting galleries and museums lower than any other pastimes (Halliday and Astafyeva, 2014). Thus, key to engaging with this age group in free time activities should be a focus on targeting their desire for social interaction, involvement and co-creation of experiences that may also take place in or be facilitated in the virtual world.

A good example of such engagement is the location based ICT enabled AR game Pokémon Go. The first week of Niantic's launch of Pokémon Go in July 2016 engaged 65 million users with the game (Serino et al., 2016). By October 2016, the number of gamers had stabilised to around 15.4 million active users each week (Pokémon Go Hub, 2016). Based on USA user data, it was found that in the weeks immediately post-launch, 22 per cent of all gamers fell within the 13-17 age range, with 46 of all gamers aged 18-29. It was also found that 63 per cent of all gamers were female (Sonders, 2016). By October 2016, US data shows that both the gender balance and age of gamers has shifted somewhat. Now male gamers comprise 47 per cent, and gamers, while still dominated by those aged under 30, tend to be older than at launch (30 per cent of all players are now aged 30-49). Again, across the USA, as with other popular games played on mobile devices, the game has "disproportionately been adopted in urban areas", yet it has been found that "the geographic distribution of Pokémon GO players [...] almost exactly matches the geographic distribution of the U.S. population [... ] all regions are adopting it at equal rates" (Sonders, 2016). Pokémon GO can be considered similar to the existing practice of geocaching, as basically a hi-tech version of treasure hunting, or hide and seek (Cord et al., 2015; Ihamäki, 2012).

\section{Methodology}

As a primarily conceptual paper, an inductive qualitative approach to theory building has been takes based on our analysis and understanding of an existing practice (geocaching) that is undertaken among a community of practitioners (geocachers). This has resulted in our presentation of a conceptual framework, which is the theory itself that we have constructed from our understanding of what is going on and which principles can then be applied across other tourism practices.

While conceptual framework can be considered as "an argument about why the topic one wishes to study matters, and why the means proposed to study it are appropriate and rigorous" (Ravitch and Riggan, 2012: p. xiii), and thus a means of organising and presenting the design of empirical data collection, a conceptual framework can also be perceived as "a way of linking all of the elements of the research process" including the method itself (Ravitch and Riggan, 2012, p. 6). Miles and Huberman (1994, p. 18) propose that developing a conceptual framework involves understanding and identifying various "intellectual bins" associated with "the main things to be studied - the key factors, concepts, or variables - and the presumed relationships among them". These factors can also include behaviour and activities. It is this setting out and naming these bins that leads to the development of the conceptual framework. They also explain that a conceptual framework may be either visual, graphically identifying these bins and their presumed relationships, or may be written, with a narrative explanation. What follows is our written narrative explanation, and also a visual representation of the conceptual framework we present of the practice of geocaching and the community of geocaching practitioners. As such, in this case, the conceptual framework does not lead to the development of empirical research design, but rather is the theory itself, presenting what we have constructed from our understanding, and helping the reader understand what we think is going on regarding the phenomenon under investigation (Maxwell, 2013).

\section{Discussion of findings}

\section{Conceptualising geocaching as a social practice}

The location-based leisure sport of geocaching involves participants creating a cache (or hidden "treasure"), and hiding it at an interesting place so others may employ GPS technology to locate it. 
That people involved in geocaching are constantly searching for these hidden treasures has resulted in geocaching being frequently described as a hi-tech version of treasure hunting, or hide and seek (Cord et al., 2015; Ihamäki, 2012) and its participants as "Human search engines". In this recreational sport a box containing small gifts, toys, key rings or coins is hidden at a public location that might be of interest to other people, e.g. as a result of its history, beauty or landscape. The box will also often contain a small log book in which finders of the cache will log their visits along with a short message. The cache hider then publishes the co-ordinates of the location (the "waypoint") on the community's web page, sometimes with clues and other relevant geographic information about the location. A puzzle may also have to be solved to get the exact location co-ordinates of a given cache. Armed with this information and a personal GPS, cache hunters set off to find the hidden treasure. On entering the waypoint the GPS shows the approximate location of the cache. After locating the cache, the "hunter" then returns to the geocaching web page to log their find and write their experiences and comments about the treasure to be read by community members. Another interesting artefact employed in geocaching is the "travel bug" - special metal "bugs" created specifically to go on a travel expedition around the globe. The bugs are often named, have a travel aim and a supporting personal page on the geocaching web page (Peters, 2004) and may be hidden near airports (travel bug hotels). A travelling geocacher is instructed by the cache creator to take it with him/her to hide again at their destination.

However, despite wide engagement with the practice of geocaching, there is little conceptualisation of it in theory, and limited literature considering the way the technological and social elements of what is essentially a pastime could augment business practice specifically in the tourism sector. Moreover, many caches tend to be hidden close to urban settlements, thus there is even less research into the practice of geocaching in rural and less-developed areas (Cord et al., 2015).

The practice of geocaching is conceptualised as the object of a community of practitioners (Geocachers), and the practitioners as the subject of the object (Geocaching). Geocachers are considered therefore not only as consumers, but also as creators of the tourism experiences for those in future who seek and find the caches (Ihamäki, 2012). We argue not only is it the continual enactment of the practice that both increases its use and develops its content that is an important aspect of geocaching as a practice, but also that by engaging with the practice, organisations in the tourism sector can contribute to the way that the practice develops and is used to enhance the destination experience - both for current geocachers, and for those who have yet to engage with this practice.

The community of geocaching practice is large and growing. The practice of geocaching emerged in the year 2000, but already by 2015 had engaged over 6 million active players globally searching for almost 2.7 million active caches (Cord et al., 2015). The "virtuality" of the web-based element of the practice is significant, and different from other forms of practice, since the absence of spatial and temporal limits (Brown, 2002) enables the community to function without corporeal involvement. Apart from the online contact with members of the community, people also frequently organise what they call "cache events" where interested community members attend to socialise and share ideas on their individual practices and go on group cache hunting expeditions. Geocaching is a materially mediated nexus of activity. It embodies capacities such as know-how and dispositions and has materially mediated arrays of human activities which are centrally organised around shared skills and practical understandings (Schatzki, 2001). It is a practice because it is made up of an evolving nexus of activities and mediated by artefacts. The generic routine activities of cache-creation, hiding and searching, etc. constitute the building blocks of geocaching. Geocaching, in respect of gamification in tourism, can also be seen to provide meaning for tourists through providing intrinsic rewards such as relatedness (to other geocachers); the ability to be engaged by players of various levels of competence, and autonomy, whereby players can drop in and out of the game as they chose (Xu et al., 2014). There are also basic rules and guidelines that are to be followed in enacting these activities. For example a geocacher will have to seek permission before hiding a cache at any public place. There are also distinct customs and shared practices of writing a message in a cache visitors' log book, recording ones' finds on the internet, etc. Membership of this community therefore requires the acceptance of these distinctive customs and shared practices. However, these shared activities 
of the community of geocachers are not governed by a given set of ideas, theories or laws - one of the major attributes or dimensions of what constitutes a practice as advocated by Barnes (2002). Notwithstanding this, in making sense of the social activities making up the practice of geocaching, the activities are not understood as a mere building block of practice which are supposed to be enacted just for the sake of the practice, but their enactments are goal oriented and are based on experience and intelligibility of actors. Tsoukas (1998, pp. 54-5), drawing on the classical theory of morality as advanced by Mclntyre (1985), identified the "four crucial features" of a practice.

A practice is a complex institutionalised social activity. The key features of a practice in this context are outlined below (for a more detailed exploration of these issues see Sarpong, 2008). A practice is "a complex form of social activity that involves the cooperative effort of human beings; it is coherent and, therefore, bound by rules and it is extended in time". Mclntyre goes on to explain that practices are institutionalised and that the underlying logic is that "although practices alone are articulate forms of social action, if they are to be sustained, they will inevitably become institutionalized". The idea of individuals taking personal responsibility for the safe transfer and movements of key artefacts like travel bugs and geocoins and maintaining caches, are just a few examples of the cooperative efforts of actors in working together to sustain their shared understanding of practice.

A practice requires participation. Every practice also establishes a set of what Mclntyre calls "internal goods", meaning goods that cannot be achieved in any other way but by participating in the practice itself. It therefore behoves on an actor to fully participate in a practice to fully engage in a practice, to appreciate and share in the collective practice and understanding of the practice. The creation of caches "which is an integral part of the caching experience" (O'Hara et al., 2007, p. 8), including the analytical skills required in solving puzzles to find location co-ordinates, the sometimes laborious activity of searching, and the associated thrill in finding a cache and exploring novel locations, cannot be achieved except by participating in the practice of geocaching. While an individual may enjoy this experience during a hunting expedition, the person who hid the treasure also enjoys all the thrills involved in preparing and hiding the cache, as well as being able to share his/her view about a particular location with an unknown person. This implies the "internal goods" delivered by geocaching do not benefit an individual alone, but rather the community of geocachers, by continuing the advancement of the generic social aspect of the practice.

A practice sets standards of achievement. Participating in a practice also "involves attempting to achieve standards of excellence operative in the practice at the time" (Mclntyre, 1985). Orienting oneself to others requires accepting the collective standards of the practice and making conscious efforts to achieve and maintain them as espoused by the practice so as to become a competent member of the community. This is an intrinsic part of geocaching. As O'Hara et al. (2007) found out, the collection of cache finds serve as a demonstrable record of what one has achieved with reference to other people. Some people can be driven to set targets for themselves which then serve as an additional incentive for them to excel in their practice.

A practice has a history of development. Finally, "every practice has its own history which is not only the history of the changes of technical skills relevant to the practice, but also a history of the changes of the relevant ends to which the technical skills are put" (Mclntyre, 1985). The evolution and history of geocaching can be traced back to GPS signals being made available for civilian use by the US Government, and when the first cache was hidden by Dave Ulmer on 3 May 2000 (Peters, 2004), through to its current status as a global activity. As a result of the continuous improvements in its associated artefacts, the continuous transformation of the skills required to participate, and the incremental improvement and understanding of the shared practices, geocaching can be seen to be in a constant flux of transformation. The activities underlying the practice are dynamic and the continuous expansion of their scope to meet local context by individuals and groups is a testimony that geocaching is never static but is in a constant process of becoming (Tsoukas and Chia, 2002) (Figure 1).

Although enabled through ICT, the cache creation, search and event activities associated with the practice of geocaching occur in physical places, many of which would remain unknown to those who had not engaged with the practice.

\begin{tabular}{l|l|l} 
PAGE 98 & JOURNAL OF TOURISM FUTURES & VOL. 4 NO. 12018
\end{tabular} 


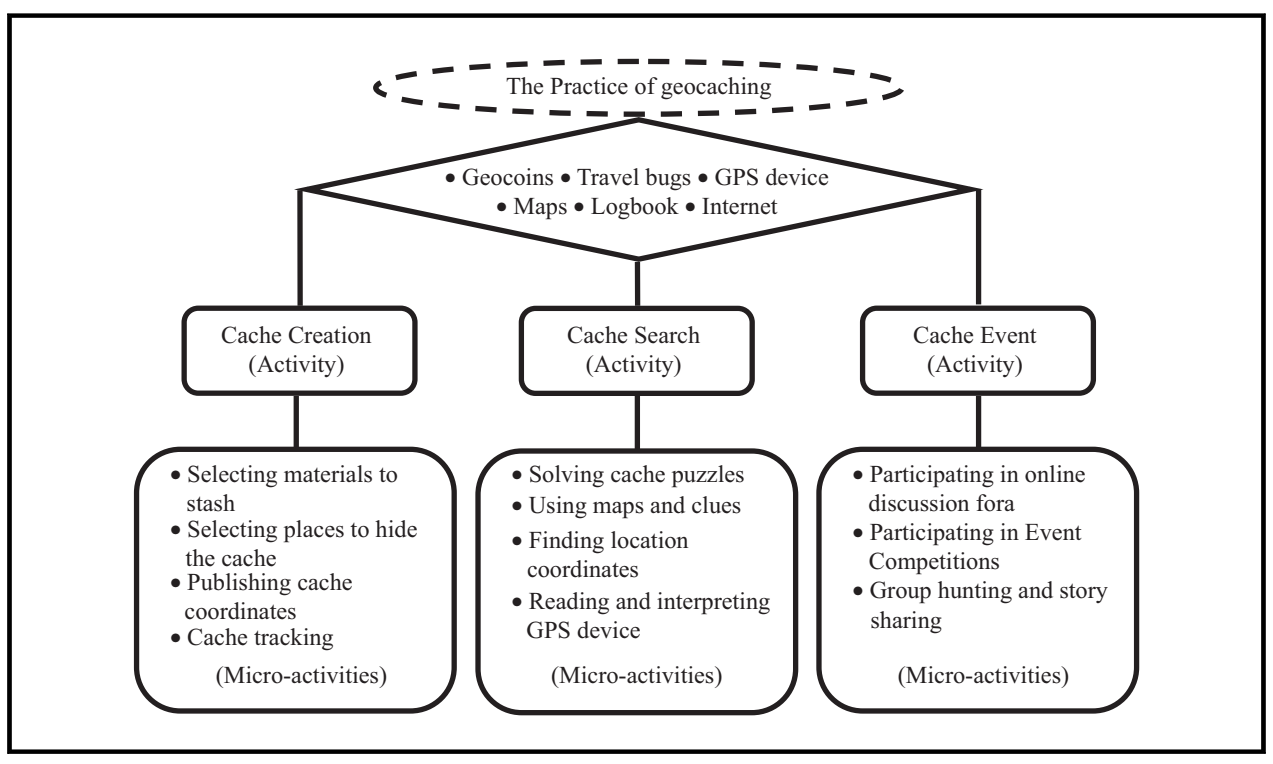

\section{Mobile technology and tourism}

Despite the size and exponential growth of the community of geocaching practice only a very limited amount of scholarly work has concentrated on this phenomenon (Witcher, 2010). Ihamäki (2012, p. 153) believes that "within the domain of location-based creative tourism experience, geocaching represents on interesting and important object of study", and her small scale (52 person response) survey considered the implications of geocaching to social interaction and tourism, but this was contextualised specifically to adventure tourists and adventure tourism destinations. Chavez et al. (2004), in a small scale exploratory study, developed a demographic picture of current geocachers. They found that a large majority of the people who are actively engaged in the sport are white males with some College education. O'Hara et al. (2007), in an exploratory study to understand the practices and motivation of geocachers, found that the idea of walking with other people and the possibility of exploring different places are some of the major incentives that motivate people to go geocaching. This is borne out by Fielding (n.d.) who found "examples of areas where the landowners are actively promoting geocaching as a way of encouraging more walking on their property. For instance the National Trust is planning on setting up a series of geocaches along the Wey navigation in Guildford, UK as a way to encourage more visitors to walk along the river rather than just staying at the visitor centre".

Grey (2007) discusses geocaching as "an exciting game using GPS that provides place-based information regarding [...] public lands, facilities and cultural heritage programs", placing it in the domain of a "place-based learning activity" (p. 285). Similar uses of geocaching are to be found in Witcher's (2010) study of geocaches hidden near Hadrian's Wall. It is Witcher's work that, while focussing on existing communities of geocachers, also considers the wider uses of mobile technology for tourism, especially those technologies which allow the sharing of digital content by users.

Çeltek (2010) highlights the entertainment value potential to tourism offered by mobile technology. She believes that there are further opportunities to be brought to tourism marketing from the use of "advergames" such as Geocaching, especially by taking advantage of the opportunities offered by the sheer number of people purchasing mobile devices upon which such games can be played, and by the rise in the number of people actively seeking entertainment from these devices. Rusu and Cureteanu (2009, p. 67) also note the link between the use of smart phones and their application to tourism through taking advantage of "Quick Response (QR) codes or mobile tagging". They further note the use of smart phones for acquiring real-time trip-related information, 
uploading photographs and diary notes of a trip during the trip, in addition to "causing a second shift in how travel is purchased".

Interestingly, while Leo (2010, p. 15) points to the fact that "mobile phones with GPS receiver open yet another group of people that could participate in these games", the practice has not yet really widened outside of the die-hard geocaching community. Indeed, Witcher (2010) stresses that, while the pervasiveness of mobile technology means that anyone can join in this practice, it is, currently, "exclusive - players must not disclose geocache locations to the uninitiated". With more of a focus on applications of the technology itself, Poslad et al. (2001) discuss the need "to build new information delivery and service integration systems for a far more heterogeneous tourist population than any system in the past". These authors also point to the changing nature of the contemporary tourist who may be combining "several purposes with travelling, such as business, leisure, entertainment, and education", stressing that the need to "personalise tourism services is based on automatic user localization". Tussyadiah and Zach (2012, pp. 781-2) similarly argue "that tourists go through the process of geographic knowledge acquisition and representation as they move to and within a destination, and use spatial knowledge to gain a meaningful tourism experience", and that ICT becomes both "relevant and important" due to the very "spatiotemporal nature of travel". Therefore "the development of location-aware or context-aware technologies has opened access for tourists to various venues for retrieving geographic information before, during and after traveling". However, the extant literature on such technologies in tourism is limited to the technological developments, rather than "how the different types of geographic technologies influence the ways tourists experience the destinations beyond the practical point of view of navigation and way-finding". In their study of 15,000 American respondents, on their most recent trip:

$74.2 \%$ of respondents used geo-based applications/software on computers, $72.8 \%$ used car navigation system, 43.4\% used location-based applications on smart phones, $30.1 \%$ used portable audio guides (for museums, etc.), and $22.2 \%$ used portable GPS devices (for hiking etc.) (Tussyadiah and Zach, 2012, p. 787).

Engaging with geocaching was mentioned by 6.7 per cent of respondents, but in Tussyadiah and Zach's study that figure aggregates "uses such as geo-caching or retrieving weather information", so exact numbers who engaged specifically with geocaching are difficult to establish. Overall, these authors found that acquiring "Landmark Knowledge" and "Route Knowledge" remains a primary purpose for tourists' use of geo-based technology, coupled with "Survey Knowledge" which they define as "the comprehension of an orientation of or an interrelation between one landmark (or one route) and another". Thus, the knowledge gained about places through geo-technology "assists people to enjoy their travel and gain meaningful experience [...] the use of geo-based technology by tourists not only helps them with finding locations within a destination, it was found that geo-based technology also assists them with the dimensions of sensory and emotion, as well as cognition and interaction".

Examples: QR codes, geocaching, and trails. Monmouth, a town in Wales, has been at the centre of the "MonmouthpediA" project that uses QR codes to enable visitors to the town's Shire Hall to access a guided tour and information about the venue, and to use the venue as the starting point for a number of other trails around the town and its areas of interest. This project prompted news headlines to refer to Monmouth as "the world's first Wikipedia town" (Monmouthshire County Council). However, this initiative is project-driven and commands the use of specific format QR codes. Codes associated with the project "may not use standard black and white QR codes, in order to differentiate between MonmouthpediA codes and other schemes and individual's codes" (MonmouthpediA). While such "rules" retain the integrity of the project it does not encourage wider engagement in a community of practice outside of the project itself, and does not encourage local businesses to adopt and adapt the technology for their own purposes. We argue that similar initiatives, but managed in a much less top-down and project-driven manner, could utilise location-based technology, and incorporate the gamified nature of geocaching, to enhance the tourist experience at a destination.

While there remains much potential for organisations within the tourism sector to collaborate locally to develop geocaching trails which may engage both current geocachers, and those new to the practice, the financial value of engaging with geocaching is also not to be underestimated, 
but has not been paid much attention in the literature. In one article (Ouellet, n.d.), examining geocaching in Canada, it was estimated that in one year alone geocaching "had an \$887 million impact in Monroe County and accounted for almost 14,000 jobs".

There are other more recent examples of the way geocaching is currently practiced, and also the way geocaching trails have been initiated to attract tourists who may yet to have engaged with practice, that can be found in the tourist destination of Corfu, a relatively small island in the lonian Sea, with one large main Town, a number of small villages set in its mountainous central and inland regions, with most of the island's tourism taking place along its' coastal resorts. Real Corfu (n.d.) offers insights into the way geocaching is practiced on the island by the geocaching community. One geocaching enthusiast initially became involved after hearing that (in early 2015) there were already 50 caches hidden around the island. His narrative account of one experience shows the way this technologically enabled practice does not require the level of technological infrastructure employed in smart cities to still provide an exciting experience for the geocacher:

We got to the area showing by an app I downloaded, I couldn't really see where it could be hidden. I heard of micro caches with magnets so I run my fingers on a metal grill and I felt an anomaly which I picked off with a pinch. It was a tiny metal magnetic cache [...] I had to wait about 5 minutes before putting it back to where I found it as there was a couple taking pictures and talking close by and I didn't want them to see me putting it back it. Again I logged my findings on the site later in the day and researched from more caches (realcorfu.com).

The Pentati Pirate Trail geocaching treasure hunt was specifically created as part of the village project to attract more tourists to this small fishing village on Corfu. The Pentati Pirate Trail is similar to the MonmouthpediA project in that it is accessible in a relatively low-tech way, through "a narrated audio version with local actors [...] available for those with smart phones and devices with QRC readers" (pentati.com). However, the Pentati Pirate Trail also employs the principles and practices of geocaching, gamifying the tourist experience, and attracting people who may never have engaged previously with geocaching. This project also positions the geocaching experience as one that is cohesive, is specific to the village of Pentati, involves collaboration between local independent entrepreneurial businesses, and offers not only the treasure hunting experience, but an entire narrative around a fictional raid by pirates on the village.

\section{Implications for the future of tourism}

In summary a concerted and co-ordinated effort towards local business collaboration is required to engage tourists in geocaching in order to enhance the destination experience, thereby institutionalising and ensuring the sustainability of the community of practice. We also therefore propose that there is a role to be played by destination marketing organisations, and also by smaller informal groups of entrepreneurial tourism-related businesses within destinations, in creating and developing such geocaching trails, to engage not only existing communities of geocachers, but also to engage other visitors with this practice, particularly Millennials and Generation Z, who tend to seek richer digital and often gamified tourism experiences. Moreover, by conceptualising geocaching as a community of practice as outlined in the conceptual framework presented in this paper, and offering such activities in a destination in a co-ordinated manner, can meet the needs of Millennials and Generation Z for participatory social activities that are gamified, and that both recognise and also reward standards of achievement.

Through an understanding of the practice of geocaching, local businesses in Europe can engage tourists with activities such as cache creation and cache search, even hosting regular cache events throughout the tourist season. The activities and micro-activities that so appeal to Millennials and Generation Z, such as solving cache puzzles; using maps and clues; finding location co-ordinates; and reading and interpreting GPS device involved in cache search can be promoted through local tourism business premises. This can be coupled with the use of either simply created QR codes (Rusu and Cureteanu, 2009) or even AR applications that enable the transmission of richer digital content, which would then be scanned using a mobile device, to point to other caches or content that could be of interest to tourists. It is therefore the extent of local businesses' engagement with the practice and not necessarily the sophistication of the technological infrastructure of the destination that is fundamental to ensuring the effectiveness 
and sustainability of geocaching as a practice for the purpose of tourism. This broader application of geocaching exemplifies the continual development of shared social practices (Tsoukas and Chia, 2002; Mclntyre, 1985). The practice would retain the entertainment value of a game as proposed by Çeltek (2010), but be more akin to a "place-based learning activity" as proposed by Grey (2007), while also offering the tourist-valued landmark, route and survey knowledge as identified by Tussyadiah and Zach (2012). This has the potential to widen not only the activities with which visitors could engage through the application of mobile based technology to include photosharing, and adding richness to the visitor experience, by enabling downloading of more information about the destination and its heritage (Witcher, 2010), but also widening the community of those who could engage with geocaching (Leo, 2010). By considering this conceptual framework, the tourism sector can harness this wave of mobile GPS-based technology to widen engagement with the practice of geocaching. By engaging with existing practice and thereby shaping it, such organisations will no longer remain at the mercy of technology, but can determine (at least to some degree) how the technology can serve the sector.

\section{Originality}

The theoretical contribution of this paper is the presentation of this framework that conceptualises geocaching as a community of practice.

The practical application of this contribution is the way such a conceptualization can open up space and place, particularly non-urban places, rural destinations, and also tourism destinations on the less technologically enabled or resource-rich side of the digital divide. Organisational engagement with an existing practice such as geocaching could attract not only existing communities of geocachers to visit a particular destination, but also to engage better with Millennials and Generation Z through the practice of geocaching as a gamification enhancement to the destination experience. By doing so, even relatively small entrepreneurial businesses in such destinations could actually reap the benefits of employing the principles and practices associated with smart tourism, albeit on a smaller scale.

\section{References}

Barnes, B. (2002), "Practice as collective action", in Schatzki, T., Knorr Cetina, K. and Von Savigny, E. (Eds), The Practice Turn in Contemporary Theory, Routledge, London, pp. 17-28.

Boes, K., Buhalis, D. and Inversini, A. (2015), "Conceptualising smart tourism destination dimensions", in Tussyadiah, I. and Inversini, A. (Eds), Information and Communication Technologies in Tourism 2015: Proceedings of the International Conference in Lugano, Springer, Cham, 3-6 February, pp. 391-403.

Brown, N. (2002), "Community metaphors online: a critical and rhetorical study concerning online groups", Business Communication Quarterly, Vol. 65 No. 2, pp. 92-100.

Buhalis, D. (2000), "Marketing the competitive destination of the future", Tourism Management, Vol. 21 No. 1, pp. $97-116$.

Buhalis, D. and Amaranggana, A. (2014), "Smart tourism destinations", in Xiang, Z. and Tussyadiah, I. (Eds), Information and Communication Technologies in Tourism 2014: Proceedings of the International Conference in Dublin, Springer, Cham, 21-24 January, pp. 553-64.

Çeltek, E. (2010), "Mobile advergames in tourism marketing”, Journal of Vacation Marketing, Vol. 16 No. 4, pp. 267-81.

Chavez, D., Courtright, R. and Schneider, I. (2004), "Over the river and through the woods", Parks \& Recreation, Vol. 39 No. 4, pp. 68-72.

Cord, F., Roeßiger, F. and Schwarz, N. (2015), "Geocaching data as an indicator for recreational ecosystem services in urban areas: exploring spatial gradients, preferences and motivations", Landscape and Urban Planning, Vol. 144, December, pp. 151-62.

Egger, R. and Buhalis, D. (Eds) (2008), "Mobile systems", eTourism Case Studies: Management and Marketing Issues, Buttherworth-Heinemann, Oxford, pp. 417-25. 
Fielding, A. (n.d.), "Cyber space, meat space and a sense of place: lessons from the interplay of the online and offline worlds”, (Internet), available at: www.walk21.com/papers/Andrew\%20Fielding_Cyber\%20Space,\%20 Meat\%20Space\%20and\%20a\%20Sense\%20of\%20Place.pdf (accessed 20 December 2011).

Greaves, N. and Skinner, H. (2010), "The importance of destination image analysis to UK rural tourism", Marketing Intelligence and Planning, Vol. 28 No. 4, pp. 486-507.

Gretzel, U., Sigala, M., Xiang, Z. and Koo, C. (2015), "Smart tourism: foundations and developments", Electron Markets, Vol. 25 No. 3, pp. 179-88.

Grey, H.R. (2007), "Geo-caching: place-based discovery of Virginia state parks and museums", Journal of Museum Education, Vol. 32 No. 3, pp. 285-92.

Halliday, S.V. and Astafyeva, A. (2014), "Millennial cultural consumers: co-creating value through brand communities", Arts Marketing: An International Journal, Vol. 4 Nos 1/2, pp. 119-35.

Han, D.-I., Jung, T. and Gibson, A. (2014), "Dublin AR: implementing augmented reality in tourism”, in Xiang, Z. and Tussyadiah, I. (Eds), Information and Communication Technologies in Tourism 2014: Proceedings of the International Conference in Dublin, Ireland, Springer, Cham, 21-24 January, pp. 511-23.

Ihamäki, P. (2012), "Geocachers: the creative tourism experience", Journal of Hospitality and Tourism Technology, Vol. 3 No. 3, pp. 152-75.

Leo, H. (2010), "Trends in service innovation enhanced by mobile services in the field of tourism in rural and mountain areas", Aosta Seminar: How can service innovations support sustainable tourism in rural regions?, Saint Vincent, Valle D'Aosta, 21-23 November.

Linaza, M.T., Gutierrez, A. and García, A. (2014), "Pervasive augmented reality games to experience tourism destinations", in Xiang, Z. and Tussyadiah, I. (Eds), Information and Communication Technologies in Tourism 2014: Proceedings of the International Conference in Dublin, Ireland, Springer, Cham, 21-24 January, pp. 497-509.

Maxwell, J.A. (2013), Qualitative Research Design: An Interactive Approach, Sage, Thousand Oaks, CA.

Mclntyre, A. (1985), After Virtue, 2nd ed., Penguin, London.

Miles, M.B. and Huberman, A.M. (1994), Qualitative Data Analysis, Sage, Thousand Oaks, CA.

Neuborne, E. (1999), “Generation Y today's teens - the biggest bulge since the boomers - may force marketers to toss their old tricks", Business Week, 15 February, p. 80.

O'Hara, K., Kindberg, T., Glancy, M., Baptista, L., Sukumaran, B., Kahana, G. and Rowbotham, J. (2007), "Collecting and sharing location-based content on mobile phones in a zoo visitor experience", Computer Supported Cooperative Work, Vol. 16 No. 1, pp. 1573-7551.

Ouellet, S. (n.d.), "Mapping and inventory of cultural sites in highlands east", (Internet), available at: www.haliburtoncooperative.on.ca/literature/pdf/TP642HighlandsEastCulturallnventory.pdf (accessed 20 December 2011).

Pentati Pirate Trail (Internet), available at: www.pentati.com/pirates.html (accessed 29 January 2016).

Peters, J. (2004), The Complete Idiot's Guide to Geocaching, Alpha Books, New York.

Pokémon Go Hub (2016), “Is Pokemon GO dying? Let's explore data!”, 14 October, (Internet), available at: http://pokemongohub.net/pokemon-go-dying-lets-explore-data/ (accessed 18 October 2016).

Poslad, S., Laamanen, H., Malaka, R., Nick, A., Buckle, P. and Zipf, A. (2001), "CRUMPET: creation of user-friendly mobile services personalised for tourism", 3G 2001. Second International Conference on 3G Mobile Communication Technologies, London, March.

Quadri-Felitti, D. and Fiore, A.M. (2016), "Wine tourism suppliers' and visitors' experiential priorities", International Journal of Contemporary Hospitality Management, Vol. 28 No. 2, pp. 397-417.

Ravitch, S.M. and Riggan, M. (2012), How Conceptual Frameworks Guide Research, Sage, Thousand Oaks, CA.

Real Corfu (n.d.), "Geocaching in Corfu", (Internet), available at: http://realcorfu.com/geocaching-corfu/ (accessed 13 June 2015).

Rusu, S. and Cureteanu, R. (2009), "International tourism evolution and smartphone impact on tourism", Journal of Economics and Business Research, Vol. XV No. 2, pp. 64-8. 
Sarpong, D.B. (2008), "A practice centred approach to understanding social learning and knowledge creation in a 'community of practice' ", International Journal of Business and Management, Vol. 3 No. 4, pp. 23-36.

Schatzki, T. (2001), "Introduction: practice theory", in Schatzki, T., Knorr Cetina, K. and Von Savigny, E. (Eds), The Practice Turn in Contemporary Theory, Routledge, London, pp. 1-14.

Serino, M., Cordrey, K., McLaughlin, L. and Milanaik, R.L. (2016), "Pokémon Go and augmented virtual reality games: a cautionary commentary for parents and paediatricians", Current Opinion in Pediatrics, Vol. 28 No. 5, pp. 673-7.

Solka, A., Jackson, V.P. and Lee, M. (2011), "The influence of gender and culture on Generation Y consumer decision making styles", The International Review of Retail, Distribution and Consumer Research, Vol. 21 No. 4, pp. 391-409.

Sonders, M. (2016), "Pokémon GO demographics: the evolving player mix of a smash-hit game", (Internet), available at: www.surveymonkey.com/business/intelligence/pokemon-go-demographics/ (accessed 18 October 2016).

Tapscott, D. (2009), Growing Up Digital: How the Net Generation is Changing Your World, McGraw-Hill, New York, NY.

Thomas, M. (Ed.) (2011), Deconstructing Digital Natives: Young People, Technology and the New Literacies, Routledge, New York, NY.

Tsoukas, H. (1998), "Forms of knowledge and forms of life in organised contexts", in Chia, R. (Ed.), The Realm of Organisations: Essays for Robert Cooper, Routledge, London, pp. 43-66.

Tsoukas, H. and Chia, R. (2002), "On organizational becoming: rethinking organizational change", Organization Science, Vol. 13 No. 5, pp. 567-82.

Tussyadiah, I.P. and Zach, F.J. (2012), "The role of geo-based technology in place experiences", Annals of Tourism Research, Vol. 39 No. 2, pp. 780-800.

Valentine, D.B. and Powers, T.L. (2013), “Generation Y values and lifestyle segments”, Journal of Consumer Marketing, Vol. 30 No. 7, pp. 597-606.

Williams, K.C. and Page, R.A. (2011), "Marketing to the generations", Journal of Behavioral Studies in Business, Vol. 3, April, pp. 1-17.

Witcher, R.E. (2010), "The fabulous tales of the common people part 2: encountering Hadrians Wall", Public Archaeology, Vol. 9 No. 4, pp. 211-38.

Xu, F., Weber, J. and Buhalis, D. (2014), "Gamification in tourism", in Xiang, Z. and Tussyadiah, I. (Eds), Information and Communication Technologies in Tourism 2014: Proceedings of the International Conference in Dublin, Ireland, Springer, Cham, 21-24 January, pp. 525-37.

\section{Further reading}

MonmouthpediA (n.d.), "MonmouthpediA", (Internet), available at: http://en.wikipedia.org/wiki/Wikipedia: GLAM/MonmouthpediA (accessed 13 January 2012).

Monmouthshire County Council (2012), "Monmouth becomes the world's first Wikipedia town", (Internet), available at: www.monmouthshire.gov.uk/news/article/587/monmouth_becomes_the_worlds_first_ wikipedia_town (accessed 13 January 2012).

\section{Corresponding author}

Heather Skinner can be contacted at: heatherskinnercorfu@gmail.com

For instructions on how to order reprints of this article, please visit our website: 